\title{
Radiation Synthesis of Psyllium/Frankincense Essential Oil - Based Wound Dressing Hydrogels: Antimicrobial, Antioxidant and Wound Healing Performance
}

\author{
Amany I. Raafat a ${ }^{\text {, Eman Araby }}{ }^{\text {b*, Sawsan M. El-sonbaty }}{ }^{\text {b }}$ \\ (a) Polymer Chemistry Department, National Center for Radiation Research and Technology, Egyptian Atomic Energy Authority \\ (AEAE), P.O. Box 29, Nasr City 11731, Cairo, Egypt. \\ (b) Radiation Microbiology Department, National Center for Radiation Research and Technology, Egyptian Atomic Energy \\ Authority(EAEA), P.O. Box 29, Nasr City 11731, Cairo, Egypt.
}

\begin{tabular}{l} 
ARTICLE INFO \\
\hline Article history: \\
Received: $25^{\text {th }}$ Jun. 2020 \\
Accepted: $15^{\text {th }}$ Feb. 2021 \\
\hline Keywords: \\
Bioactive hydrogel dressing; \\
Frankincense Oil; \\
Antimicrobial performance; \\
Pathogenic microorganisms; \\
Wound healing
\end{tabular}

\section{INTRODUCTION}

Growing awareness for the essential aspect of wound care or any trauma helped in the development of newer strategies and approaches for innovative dressing materials with therapeutic support to enhance the quality of human life[1]. Wounded skin may cause severe health problems to the human body such as loose thermal insulation, body fluid, electrolytes, and nutritional components [2]. Wounds are classified according to the involved damaged skin layers into (a) superficial wounds in which only the epidermal layer is damaged, (b) partial-thickness wounds in which the damaged skin layers involved epidermal and deeper layers, including blood vessels, hair follicles, and sweat glands;(c) whereas wounds in which skin to the depth of subcutaneous tissues is damaged are referred to as full-thickness wounds[3]. According to the nature of the repair process wounds are referred to be acute when complete healing of wounds occurs within twelve weeks with minimal scare formation[4]; whereas wounds require a longer time for complete healing are referred to chronic[5]. Wound healing is an intricate overlapping series of well-orchestrated biological and molecular processes starting with inflammation, granulation, wound contraction, collagen deposition, and epithelialization and remodeling [6, 7]. The successful completion of such a healing process grantee the regeneration of the distorted wounded tissues and maintain its integrity and functional state. 
Accordingly, the choice of an ideal wound dressing is a pivotal requirement for the contribution in the speed-up of wound healing and promotes tissue regeneration as well as prevention of microbial infection and reduces pain.

Hydrogel-based dressings provide promising materials with new properties and treatment options that can emerge as prime candidates for wound management and repair[8]. Due to their hydrophilic nature and soft tissue-like properties hydrogels can be easily tailored to mimic the structure, physicochemical properties, and functions of the native extracellular matrix (ECM) of the skin[9]. They fulfill the essential requirements for an ideal wound dressing, including (a) cooling and soothing effect on the wounded area due to their high water content, (b) non-adhesive property that facilitates the change of the dressing without causing pain and discomfort to the patient, (c) keeping the wound moist while absorbing extensive exudate, (d) tunable mechanical properties of hydrogels provide them with suitable elasticity and flexibility to adapt to wounds location (e) hydrogels are non-toxic, nonantigenic, biocompatible and biodegradable, (f) even at their swollen state, the tight mesh size of hydrogels prevents microbial invasion while still allowing for an efficient transport of bioactive molecules such as antimicrobial and pharmaceuticals agents, (g) hydrogel permeability enables undisturbed exchange of gaseous $(\mathrm{CO} 2, \mathrm{O} 2$ and $\mathrm{H} 2 \mathrm{O})$ allowing tissue to breathe, (h) facilitate scar-free healing along with reepithelialization $[10,11]$.

Recently, psyllium seed husk arises amongst the promising natural polymers that have been used extensively in various biomedical applications due to its remarkable gelling potential. Psyllium is a complex polysaccharide obtained from herbaceous Plantago ovate. It is hydrophilic mucilage of arabinoxylan complex comprises of highly branched and densely substituted b-(1/4) linked xylopyranose (50-54\%) backbones, attached with single arabinofuranose (17$20 \%$ ) or xylopyranose, or short chains of these at 2 and 3 positions. There are also additional residues, such as rhamnose (3-5\%), and galacturonic acid (5-8\%) in these side chains[12, 13]. Psyllium has been used as a food thickener, anti-diarrheal agent, in the therapy for Crohn's disease and irritable bowel syndrome, and wound dressing's fabrication [14].

Carbopol is a commercially available cross-linked poly (acrylic acid) polymer. It is a non-irritant, nontoxic, and highly hydrophilic synthetic polymer that has been used in the development of drug delivery systems due to its high water affinity, fast swelling, high swelling ratio, and good biocompatibility. In the wound healing formulations, Carbopol hydrogels loaded with bioactive substances offer a moist environment within the wound site and therefore accelerate the healing process and improve the tissue quality of wounds[15, 16].

Nowadays, the functionalization of wound dressing hydrogels by the incorporation of bioactive moieties such as therapeutic agents and essential oils has been emerged as an innovative approach to increase the effectiveness of wound dressings, prevent microbial infection, control inflammation and stimulation of tissue regeneration and as result improving patient's compliance and comfort $[17,18]$.

Frankincense oil (FO) is an essential oil extracted from the resinous dried sap harvested from Boswellia sacra trees of the genus Boswellia native to Arabian Peninsulam(Oman, Yemen) and northeastern (Somalia)[19]. FO has been used for thousands of years as part of the practice of aromatherapy due to their therapeutic and healing properties. Traditionally, it has been used for its anti-inflammatory property, relieve chronic stress and anxiety, reducing pain, and boosting immunity. Recently, it gains a promising popular reputation for promoting skin health[20].

Even though the antimicrobial mechanism action of EOs is not completely understood, it is believed that such antimicrobial activity is due to their hydrophobicity as well as their phenolic compounds constituents, such as monoterpenes, flavonoids, and phenolic acids[21]. The hydrophobic nature of EOs facilitates the interaction with the cell membrane phospholipids of bacterial cells, resulting in increased permeability and the leakage of the inner cell components as well as affecting potassium ion reflux, and eventually leading to cell death[22]. Also, the phenolic compounds may cause a severe disturbance for the cytoplasmic membrane functions by disrupting the active transport of nutrients through the cell membrane and coagulation of bacteria cell contents [23].

Compared to other synthesis facilities, the ionizing radiation method is an excellent tool in the fabrication of materials used for biomedical applications. It is an ecofriendly additive-free process that combines synthesis and sterilization of the polymeric materials in a single technological step; thus reducing the cost and production time.

In this regard, gamma rays ionizing radiation were used to develop an innovative bioactive hydrogel dressings composed of psyllium husk (Pys) and Carbopol (Carp) enhanced with Frankincense essential 
oil to increase their utmost wound healing potential and provide them with antimicrobial and antioxidant properties.

\section{Materials and methods}

\subsection{Materials}

- Psyllium (Psy) was purchased from Sidpur Sat Isabgol factory (Gujrat, India). Carbopol 940 (Carp) was received from (Loba Chemie Pvt. Ltd., Mumbai-India). Frankincense essential oil was purchased from Ayurveda for Healthy Foods, Nasr City-Cairo, Egypt. All chemicals were used as received without further purification.

- Male Swiss albino rats (50-60 days old) weighing $(100 \pm 20 \mathrm{gm}$.) were obtained from the animal house of the National Center of Radiation Research and Technology (NCRRT), Cairo, Egypt. The animals were housed under standard laboratory conditions. Animals were maintained on a high protein commercial diet and water ad libitum and they were maintained for one week before starting the experiment as an acclimatization period.

- Ethics Statement

The study was conducted following international guidelines for animal experiments and approved by the Ethical Committee at the National Center for Radiation Research and Technology (NCRRT), Atomic Energy Authority, Cairo, Egypt.

\subsection{Methods}

\subsubsection{Preparation of (Psy-Carp)/FO Hydrogel Dressings}

(Psy-Carp)/FO hydrogel dressings were obtained by radiation-induced copolymerization using ${ }^{60} \mathrm{Co} \quad \gamma$ irradiation. Trials have been made to specify the appropriate preparation conditions for FO-loaded hydrogel dressings. At first, series of different concentrations of (Psy) has been mixed will with different percentages of (Carp) (10:50\%) from the initial weight of (Psy) and subjected to different radiation doses.

Frankincense essential oil was previously mixed with Tween 80 as an emulsifier $(0.250 \mathrm{~g} / \mathrm{g}$ of essential oil) to improve its solubility ensuring a uniform and stable distribution in the (Psy-Carp) feed solution. To the selected (Psy-Carp) optimum composition; (according to gel content and swelling studies), different concentrations of FO $(1,3,5,7$, and $10 \%)$ based on
(Psy) initial concentration were added dropwise into (Psy-Carp) mixture under magnetic stirring. The homogeneous paste-like mixtures have been cast onto glass molds then irradiated at doses 15,20 , and $25 \mathrm{kGy}$. Finally, dressings were stored at the refrigerator for further analysis.

\subsubsection{Preparation of Pseudo Extracellular Fluid (PECF)}

PECF, which simulates the wound fluids, was prepared by dissolving $0.68 \mathrm{~g}$ of sodium chloride $(\mathrm{NaCl}), 0.22 \mathrm{~g}$ of potassium chloride $(\mathrm{KCl}), 2.5 \mathrm{~g}$ of sodium bicarbonate $\left(\mathrm{NaHCO}_{3}\right)$, and $0.35 \mathrm{~g}$ of sodium dihydrogen phosphate $\left(\mathrm{NaH}_{2} \mathrm{PO}_{4}\right)$ in $100 \mathrm{~mL}$ of distilled water. The $\mathrm{pH}$ of PECF was adjusted to $8 \pm$ $0.2[24]$.

\subsubsection{Gelation Degree}

Pre-weighed (Psy-Carp)/FO hydrogel dressing samples were immersed in distilled water at $50^{\circ} \mathrm{C}$ for $24 \mathrm{~h}$ to remove the sol fraction. After that, the samples were dried in air to constant weight. The gel fraction was calculated using the following equation:

$$
\text { Gelation Degree }(\%)=\frac{G_{d}}{G_{i}} \times 100
$$

Where $G_{i}$ is the initial weight of the sample and $G_{d}$ is the weight of dried gel after extraction

\subsubsection{Fluid absorption capacity}

Imitating for an exuding open wound, pre-weighed (Psy-Carp)/FO hydrogel dressings were allowed to swell on sponge saturated with different fluids (distilled water, physiological saline solution and pseudo extracellular fluid (PECF), respectively) up to equilibrium swelling at $37^{\circ} \mathrm{C}$, thereafter the discs were taken out and gently pressed in-between two filter papers to remove excess water and finally weighed. The swelling degree $(\%)$ was determined using the following equation:

$$
\text { Swelling degree }(\%)=\frac{\mathrm{W}_{\mathrm{s}}-\mathrm{W}_{\mathrm{i}}}{\mathrm{W}_{\mathrm{i}}} \times 100
$$

Where Ws and Wi are the weights of the swollen and the dried samples, respectively. The experiments were repeated three times, and the results were reported as average values

\subsubsection{Water Vapor Transmission Rate (WVTR)}

Typically, (Psy-Carp)/FO hydrogel dressings were placed on the mouth of a cylindrical plastic cup containing $5 \mathrm{~g} \mathrm{CaCl}_{2}$ and sealed across the edges. The sets were kept at $37{ }^{\circ} \mathrm{C}$ in desiccators containing 500 $\mathrm{mL}$ saturated solution of $\mathrm{NaCl}$ (75\% relative humidity) 
and weighed at different time points. The weight loss versus time plot is then constructed and the WVTR in $\left(\mathrm{g} / \mathrm{m}^{2} \mathrm{~h}\right)$ is calculated by dividing the slope of the curve by the tested dressing area (A) using the following equation:

$$
\text { WVTR }=\frac{\text { Slope }}{\text { dressing area }}
$$

\subsubsection{Scanning Electron Microscopy (SEM)}

The morphological features of the prepared (PsyCarp)/FO hydrogel dressings were observed by scanning electron microscope (model JSM-5400 JEOL, Japan) at a voltage of $30 \mathrm{kV}$. Samples were allowed to swell till equilibrium, freeze-dried, and then the surfaces were coated with a thin gold layer to reduce charging.

\subsubsection{Antioxidant activity (DPPH Radical Scavenging Assay)}

The antioxidant efficiency of (Psy-Carp)/FO hydrogel dressings were evaluated by measuring their capacity to scavenge the stable 1, 1-diphenyl-2picrylhydrazyl (DPPH) free radical as described by (Singh et al., 2015) with minor modification[25]. A definite amount of each dressing sample was cut into small pieces and incubated with a methanolic solution of DPPH $(2 \mathrm{mM})$ for $45 \mathrm{~min}$ in dark at room temperature then after the absorbance was measured at $517 \mathrm{~nm}$ using a UV-Visible spectrophotometer (UVAnalytic Jena AG specord 210 plus). The control was conducted in the same manner, except that distilled water was used instead of the sample. The DPPH radical scavenging activity was calculated as follows:

$$
\text { DPPH scavenging } \%=\frac{A_{B}-A_{H}}{A_{B}} \times 100
$$

where $A_{B}$ is the absorption of the blank (methanolic DPPH solution) and $A_{H}$ is the absorption of the dressing (dressing sample in methanolic DPPH solution). Lower absorbance of the reaction mixture indicated a higher DPPH radical-scavenging activity. The test was carried out in triplicate.

\subsubsection{Hemolytic potential}

The hemolytic potency of (Psy-Carp)/FO hydrogel dressings were evaluated by studying their hemolytic potential according to the method described by Tomić et al [26]. In brief, dressing samples were equilibrated in $5 \mathrm{ml}$ saline water $(0.9 \% \mathrm{w} / \mathrm{v} \mathrm{NaCl})$ at $37^{\circ} \mathrm{C}$ for $2 \mathrm{~h}$ then $0.25 \mathrm{~mL}$ human ACD (acid citrate dextrose) blood has been added. After 20 minutes, $2.0 \mathrm{~mL}$ of saline water was added into the specimens to stop hemolysis and the samples were incubated for $1 \mathrm{~h}$ at $37{ }^{\circ} \mathrm{C}$. Positive or negative controls, which did not contain dressing, were performed using $0.1 \mathrm{~mL}$ of human $\mathrm{ACD}$ blood diluted with $2.0 \mathrm{~mL}$ of distilled water $(100 \%$ hemolysis) and $0.9 \%$ saline solution (0\% hemolysis), respectively. Subsequently, the absorbance of the supernatant in each tube was determined at $545 \mathrm{~nm}$ using a UV-Analytic Jena AG specord 210 plus, Germany, and the hemolysis (\%) was calculated from the following equation:

$$
\text { Hemolysis }(\%)=\frac{A \text { sample- } \mathrm{A}(-\mathrm{ve}) \text { control }}{\mathrm{A}(+\mathrm{ve}) \operatorname{control}-\mathrm{A}(-\mathrm{ve}) \operatorname{control}} \times 100
$$

Where $\mathrm{A}$ is the sample absorbance. The experiment was performed in triplicate Haemolysis value of $5 \%$ or less was considered acceptable.

\subsection{Antimicrobial Activity Evaluation}

All the next experiments were done using irradiated (Psy-Carp)/FO hydrogel dressings at $15 \mathrm{kGy}$.

\subsubsection{Preparation of Microbial Cultures}

Staphylococcus aureus (S. aureus), Escherichia coli (E. coli), and Candida albicans (C. albicans) as representatives of (Gram-positive), (Gram-negative) bacteria and fungi, respectively; were previously isolated and characterized at Microbiology Department, NCRRT. They were selected as test cells because they are the most frequent microbes in the wound infection. Cultures were grown on nutrient agar (NA) plates for $S$. aureus and E. coli and Sabouraud-Dextrose agar (SDA) for Candida albicans and maintained in the agar slants at $4^{\circ} \mathrm{C}$.

\subsubsection{Total plate count (quantitative assay)}

Antimicrobial activity of the irradiated (Psycarp)/FO hydrogel dressings was carried out according to the AATCC Test Method [27]. The evaluated (Psycarp)/FO hydrogel dressing disc in different concentrations of oils was placed in a sterile screwcapped tube; $100 \mu$ of $10^{6} \mathrm{CFU} \mathrm{ml}^{-1}$ from the different tested microbial strains was loaded on it with even distribution of the inocula. After $18 \mathrm{~h}, 900 \mu \mathrm{l}$ of sterile saline solution was added and mixed by shaking for 1 min. After that, 10 -fold dilutions in sterile saline water were made. From each dilution, $100 \mu \mathrm{l}$ was surface inoculated on NA plates. Then, the plates were incubated at $35{ }^{\circ} \mathrm{C}$ for $18 \mathrm{~h}$. Colonies were counted and log count was calculated. 


\subsubsection{Time- kill assay}

The killing assay was performed according to Tyagi et al., 2015. Microbial cells were grown in Tryptone Glucose Yeast Extract (TGY) broth medium. Using a spectrophotometer, the optical density (OD 600nm) of cells was adjusted to $0.5\left(\sim 10^{8} \mathrm{CFUml}^{-1}\right)$ in $10 \mathrm{mM}$ PBS buffer ( $\mathrm{pH}$ 7.4). A final inoculum was incubated with (Psy-Carp)/FO hydrogel dressings (including $10 \%$ oil concentration) at the chosen time points $(2,4,6$ and $24 \mathrm{~h}$ ), after that, 10 -fold dilutions in sterile saline were made. From each dilution, $100 \mu \mathrm{l}$ was surface inoculated on NA plates. Then, the plates were incubated at $35^{\circ} \mathrm{C}$ for $18 \mathrm{~h}$. Colonies were counted and the log count was calculated[28].

\subsubsection{Determination of protein release}

Each microbial suspension (control and treated with (Psy-Carp)/10\%FO hydrogel dressings at different incubation time was centrifuged at $6000 \mathrm{rpm}$ for $10 \mathrm{~min}$ at $10{ }^{\circ} \mathrm{C}$; the supernatant was used to detect the protein content[29]. A standard method using bovine serum albumin (BSA as standard) was used for calculating the amount of protein released from the microbial cells before and after the treatment with the evaluated (Psycarp)/FO hydrogel dressing.

\subsubsection{Exopolysaccharides (EPS) assay}

Microbial suspensions were centrifuged at 5000 rpm for $15 \mathrm{~min}$, the supernatant was removed and $95 \%$ ethanol was added to the cells and incubated at $4{ }^{\circ} \mathrm{C}$ overnight to release surface-bound exopolysaccharides [30]. While soluble EPS was determined in the culture supernatant directly using the phenol-sulfuric method [31]. Absorbance was measured at $490 \mathrm{~nm}$, glucose was used as standard.

\subsubsection{Microbial Surface Charge - Zeta Potential Measurement}

After the treatment with the (Psy-Carp)/FO hydrogel dressings, the surface charge of the microbial cells understudy was measured using a Nano Zeta Potential/Particle Sizer NICOMPTM 380 ZLS PSS (Nicomp Particle Sizing System, Santa Barbara, California, USA). Briefly, $100 \mu 1$ of the microbial culture was freshly inoculated in $5 \mathrm{ml}$ of Muller-Hinton broth (MHB) and incubated at $35^{\circ} \mathrm{C}$ for $360 \mathrm{~min}$, where the final microbial concentration of $\approx 1.1 \times 10^{9} \mathrm{CFU} \mathrm{m}^{-1}$ was reached $\left(0.4\right.$ at $\left.\mathrm{OD}_{590}\right)$. The microbial suspensions were then centrifuged at $10,000 \mathrm{rpm}(20 \mathrm{~min})$, the supernatant was discarded and the cell pellets were washed five times with $0.5 \mathrm{mM}$ potassium phosphate buffer solution ( $\mathrm{pH}$ 7.4). The microbial cell suspension was prepared by re-suspending the cell pellet in the used buffer. The $\mathrm{OD}_{590}$ of the final dispersion varied between 0.12 and 0.15 ; then the washed microbial cell suspension was incubated with (Psy-Carp)/FO hydrogel dressings and incubated for $1 \mathrm{~h}$ at room temperature before zeta potential measurements. For the positive control, the washed microbial cell pellets were incubated at the same conditions without any treatment[32]. The experiment was repeated in triplicate.

\subsubsection{Microbial penetration test}

The efficiency of the (Psy-Carp)/FO hydrogel dressings to prevent microbial penetration was evaluated as follows; a suspension $(20 \mu \mathrm{l})$ of $S$. aureus, E. coli and C. albicans in saline phosphate buffer $\mathrm{pH} 7.4$ was dropped on the center of the upper surface of (PsyCarp)/FO hydrogel dressings already placed on sterile nutrient agar plates that previously incubated for $24 \mathrm{~h}$ at $35{ }^{\circ} \mathrm{C}$. The suspension was carefully dropped on the dressing pieces to avoid contamination of the nutrient agar culture medium. The agar plates were then incubated for $18 \mathrm{~h}$ at $35{ }^{\circ} \mathrm{C}$ and the microbial growth on the upper surface of the dressing was visually inspected for a week. The penetration of the microbes that pass through the dressing was evidenced by colonies that grew on the agar underneath the dressing piece.

\subsection{In vivo wound healing studies}

Wound healing efficacy of the prepared (PsyCarp)/FO hydrogel dressings with different (FO) oil contents were evaluated using a rat model. In this study, Swiss male rats were anesthetized using urethin. The skin was prepared by shaving a specific surgical area from the back of each animal using an electric clipper. The shaved area was washed with $70 \%$ ethyl alcohol. A full-thickness skin wound (approximately 1 $\mathrm{x} 1 \mathrm{~cm}$ ) was created on their backs using a scissor at sites parallel and equidistant from the vertebral column. The dimensions of the wound were measured using a caliper. Rats were divided equally into 8 groups $(n=6)$ : group 1 (untreated wound) rats were covered without any dressing, group 2: wounded rats treated with dressing without oil. In the Groups from 3 to 7, rats wound was covered with dressing contain 1, 3, 5, 7and 10\% (FO) oil, respectively. Healing wound area was measured using a caliper and presented a decrease of the wound area as compared with untreated rats. New dressings were applied daily to the wound sites after cleaning with a normal saline solution. The rate of wound closure was determined using the following Eq.:

$$
\text { Wound size }- \text { reduction }(\%)=\frac{A o-A x}{A o} \times 100
$$

Where $\mathrm{A}_{\mathrm{o}}=$ wound area at day $0, \mathrm{~A}_{\mathrm{x}}=$ wound area at a specific time of the experiment. 
At the end of the experiment, the rats were sacrificed. The wound site of skin tissue was excised and one portion was used for the histopathological examination. The rest of the tissue was homogenized in $0.25 \mathrm{M}$ ice-cold isotonic sucrose to be used for the estimation of the assessed parameters.

\subsubsection{Biochemical parameters}

Biochemical parameters for inflammation and matrix formation were analyzed in skin tissue homogenates. Interleukin -6 (IL-6) was analyzed by ELIZA, based on sandwich enzyme-linked immunesorbent assay technology using Rat IL-6 ELISA Kit, MyBiosource.com. Rat Matrix Metalloproteinase 9 (MMP-9) was analyzed by ELISA kit applies the competitive enzyme immunoassay technique utilizing a monoclonal anti-MMP-9 antibody and an MMP-9-HRP conjugate, MyBiosource.com. Rat Nuclear Factor $\kappa \mathrm{B}$ (NF $\kappa \mathrm{B}$ ) Elisa kit (Competitive ELISA), applies the competitive enzyme immunoassay technique utilizing a

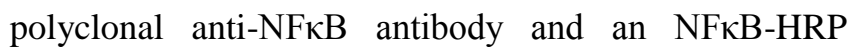
conjugate, MyBiosource.com.

\subsubsection{Histopathological examination}

Excised wound sites were fixed in $10 \%$ neutral buffer formalin and processed routinely dehydrated ascending alcohol series, cleared in xylol, embedded in paraffin wax, and cut into $4 \mu \mathrm{m}$ thickness, dewaxed, rehydrated, and stained with hematoxylin and eosin. Samples were examined using a light microscope and photographed at 40x magnification.

\subsection{Statistical analysis.}

All mean values are reported as the mean \pm standard deviation (SD). Data were analyzed using a one-way analysis of variance (ANOVA). The level of significance between mean values was set at $\mathrm{p}<0.05$ and $\mathrm{p}<0.01$ (significant and highly significant, respectively). All statistical analyses were performed using SPSS software (version 20.0).

\section{RESULTS AND DISCUSSION}

\subsection{Gelation degree}

The constancy of the hydrogels against dissolution in hot water is known as a gelation degree. The integrality of the developed network upon irradiation depends on the extent of its crosslinking density which is in direct relation with its constituent's nature, feed solution concentration, and composition as well as the preparation irradiation dose. The irradiation of (Psy-Carp) pasty mixture resulted in the simultaneous degradation of (Psy) as a naturally degradable polysaccharide, crosslinking of (Carp) as crosslinking synthetic polymer accompanied by graft copolymerization of the degradable (Psy) fragments on the cross-linkable (Carp) chains which results in the formation of an insoluble polymeric network (gel). Figure (1-a) illustrates the dependence of the gelation degree of the obtained (Psy-Carp) hydrogel dressings on the initial (Psy) concentration and the preparation irradiation dose. As can be seen, the gelation degrees ranged between 30 and $95 \%$ that increases by increasing the (Psy) concentration as well as the preparation irradiation dose. As the feed solution concentration increases, the chains of these polymers become dense and close enough for the recombination of the chain derived radicals. Additionally, the generated free radicals on both (Psy) and (Carp) increase as the irradiation dose increases consequently the crosslinking density of the developed three-dimensional network increases and the gelation degree as well.

Although the irradiation of (Psy-Carp) pasty constituents at a dose of $20 \mathrm{kGy}$ slightly improves the gelation degree of the obtained dressings than that obtained at $15 \mathrm{kGy}$, the choice of irradiation dose $15 \mathrm{kGy}$ seems economically appropriate for the formation of sufficient gel fraction.

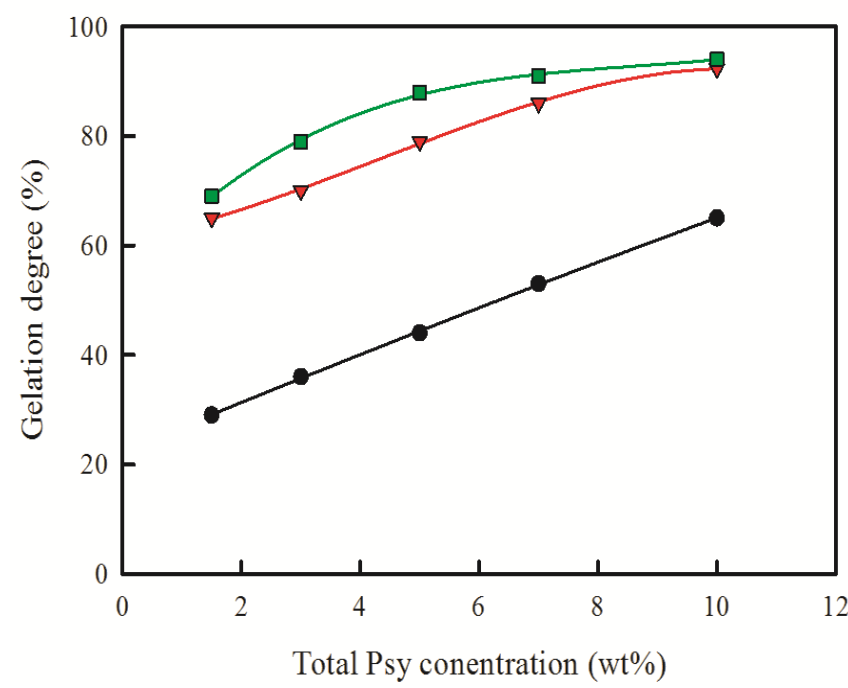

Fig. (1-a): Dependence of the gelation degree of (Psy-carp) hydrogel dressings on the initial (Psy) feed solution concentration and preparation irradiation dose $(\mathrm{kGy}):(\bullet)$ 10,( $\nabla) 15$ and $(\square) 20$; Carbopol content $(\mathbf{5 0 \%})$. 


\subsubsection{Influence of Carbopol content}

The dependence of the gelation degree of the (Psy-Carp) dressing hydrogels on their (Carp) content was illustrated in Figure (1-b). As is clear, the gelation degree of the developed dressing hydrogels increases by the increase of the (Carp) content to reach a maximum value of $88 \%$ and $96 \%$ for 3 and $5 \%$ (Pys) total feed solution concentration used during preparation, respectively. The high crosslinking tendency of (Carp) results in a well-developed 3D network structure with high gelation degree as well which makes them considerably safe to be used as wound dressing material. Accordingly, the hydrogel formulation consisting of 5\% (Psy) and (50wt \%) (Carp), from the initial (Psy) concentration, was chosen for the preparation of (Psy-Carp) hydrogel dressings supported FO essential oil.

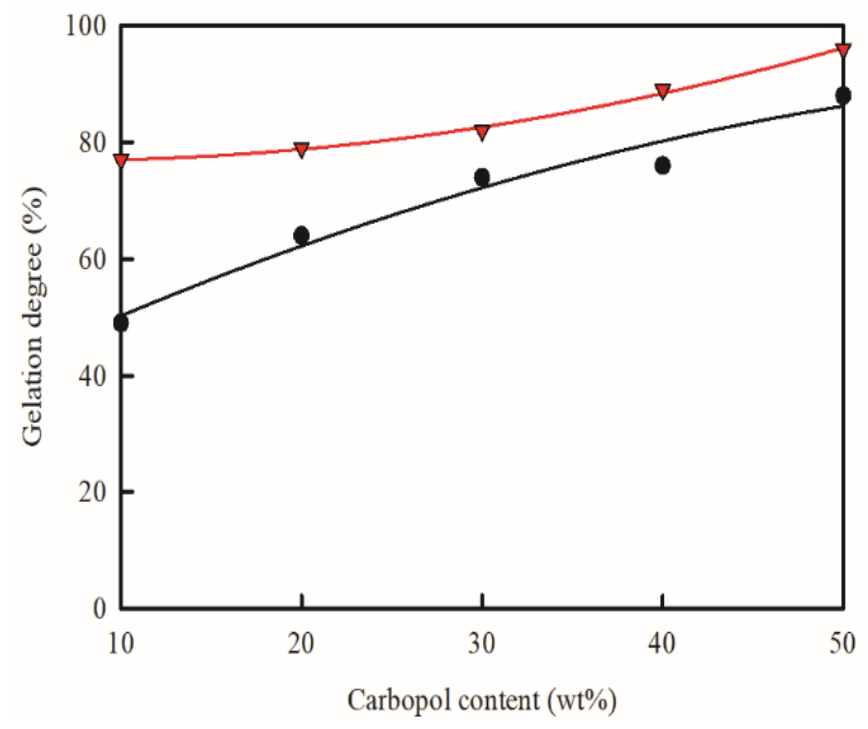

Fig. (1-b): Dependence of the gelation degree of (Psy-carp) hydrogel dressings on their carbopol content $(w t \%):(\bullet) 3$ and $(\nabla) 5:$ (Psy) concentration (3 and 5)wt\%, irradiation dose $15 \mathrm{kGy}$. Results represent the mean of three replicates

\subsection{Fluid absorption capacity}

The capability of the dressing materials to absorb wound exudates is the most significant and important prerequisites needed for ideal wound dressing. Insufficient or uncontrolled exudates absorption would results in maceration or drying out of the wound surface. The extent of the swelling degree determines the absorption capacity of wound dressing materials. The swelling behavior of (Psy-Carp) dressings incorporated different amount of FO essential oil was evaluated in water (as blood plasma contains about $90-92 \%$ of water), physiological saline solution $0.9 \% \mathrm{NaCl}$ (as its osmotic pressure is approximately equal to that of human tissue fluid) and simulated wound fluid (PECF) gravimetrically using on sponge swelling method to simulate an exuding wound and the obtained results were represented in Figure (2). Generally, it can be noticed that; the prepared dressings possess high swelling properties and the degree of swelling in water $>\mathrm{PECF}>\mathrm{NaCl}$. The incorporation of FO oil up to 5\% slightly enhance the swelling tendency of the (Psy-Carp) dressings, whereas any further increase in the FO oil content results in slight decrease in the swelling degree if compared with FO-free (Psy-Carp) hydrogel. The enhanced swelling degree of the FO loaded dressings up to $5 \%$ results in the increase in the porous structure with the addition of FO oil into the (Psy-Carp) dressing matrices which may be due to the leaching of oil droplets. Whereas due to hydrophobic nature of FO oil, increased oil content results in the acquisition of the (Psy-Carp) dressing hydrophobic properties. Since the swelling tendency of the hydrogel dressing is governed by the nature of the hydrophilic/hydrophobic balance of the dressing constituents, such decrement in swelling degree accompanied by the increase in FO oil content can be explained by the increasing crosslinking interactions between the dressing constituents and the hydrophobic FO moieties[18, 33]. Of equal importance, the ionic strength of the swelling medium is another controlling parameter that governed the swelling degree. The sensitivity of the (Psy-Carp) dressing hydrogel may be attributed to the presence of the carboxyl $(-\mathrm{COOH})$ groups along (Carp) moieties. Swelling in salt solutions or solutions of high ionic strength would result in electrostatic shielding of the ionic groups responsible for the expansion of the gel network with an easy penetration of water molecules. The increase of the swelling solution ionic strength will oppose the water diffusion into the hydrogel network results in lower swelling capability[34]. Despite the higher ionic strength of the PECF, its pH value (7.4) enables it to overcome such an obstacle. As soon as the $\mathrm{pH}$ of the swelling medium exceeds the pKa value (4.2) needed for the dissociation of $-(\mathrm{COOH})$ groups, the repulsion between the formed carboxylate - $\left(\mathrm{COO}^{-}\right)$groups along the carbopol chains result in network expansion. So, the swelling degree of (Psy-Carp)/FO dressings in $\mathrm{PECF}$ is higher than that obtained in $\mathrm{NaCl}$ solution. 


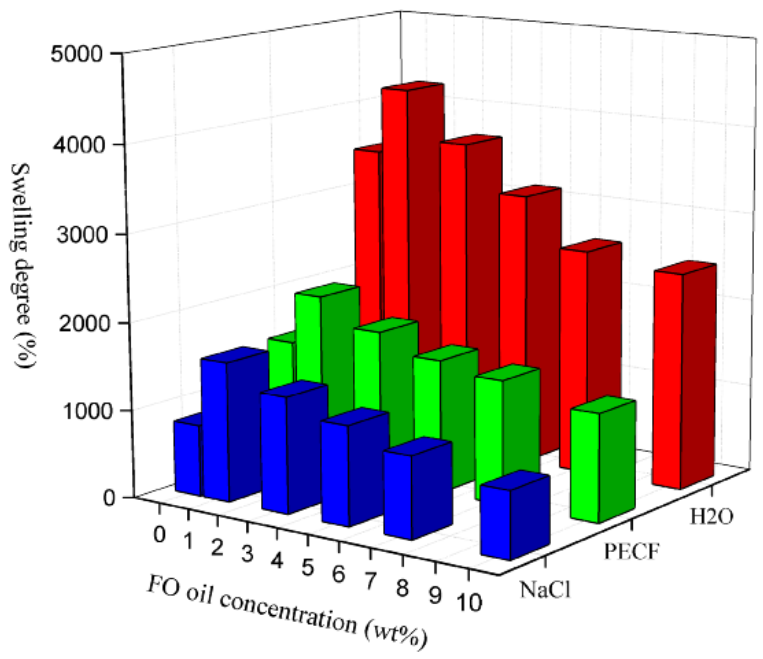

Fig. (2): Swelling behavior of (Psy-carp)/FO dressing hydrogels of different FO oil content in $(\square)$ distilled water, ( $\square$ ) PECF, and ( $\square$ ) 0.9 wt\% NaCl. Results represent the mean of three replicates

\subsection{Scanning electron microscopy}

The spongy porous features of the hydrogel dressing matrices offer a unique environment for the successful healing process. Such important criteria will enhance the dressing absorption performance consequently prohibit exudates escalation and maceration securing better tissue re-epithelization[35]. Figure3 (a:d) shows the SEM images of the (PsyCarp)/FO dressing hydrogels of different FO oil content in comparison with their FO oil-free parent hydrogel. As it is obvious, all the investigated dressings have a well-constructed three-dimensional (3D) interconnected porous foliate network structure. The incorporation of FO oil up to 5\% improves such a porous feature whereas, any further increase of the (FO) oil denser foliate network appearance with smaller pore size.

\subsection{Water vapor transmission rate (WVTR)}

The rate of water vapor transmission across the dressing surface (WVTR) is one of the most crucial parameters affecting the wound healing process. Dressing materials with excessive (WVTR) result in faster drying with the possibility of dressing attachment to the wounded skin results in eschar formation. On the contrary, dressings with low (WVTR) values leading to exudate retention, maceration of the healthy tissue surrounding the wound and opens up the risk of bacterial growth consequently retard the healing inducing patient pain. The WVTR of (Psy-Carp) hydrogel dressings incorporated different amounts of (FO) essential oil compared to the oil-free dressing was illustrated in Table (1). Generally, as can be seen, the incorporation of (FO) oil enhances the WVTR of the (Psy-Carp) hydrogels. WVTR of the oil-free (Psy-Carp) hydrogel dressing was found to be $433.2\left(\mathrm{~g} /\left(\mathrm{m}^{2} \mathrm{~h}\right)\right.$ that increased by the incorporation of 1, 3and 5\% (FO) within the hydrogel matrices to be $462.1,543.7$ and $570.5\left(\mathrm{~g} /\left(\mathrm{m}^{2} \mathrm{~h}\right)\right.$, respectively and this may be due to the additional formation of a porous structure with the incorporation of (FO) oil into the (Psy-Carp) hydrogel matrices as supported by SEM data.

Table (1): WVTR of (Psy-Carp)/FO dressing hydrogels with different FO oil content.

\begin{tabular}{cc}
\hline $\begin{array}{c}\text { Oil content } \\
(\boldsymbol{\%})\end{array}$ & $\begin{array}{c}\text { WVTR } \\
\left(\mathbf{g} /\left(\mathbf{m}^{\mathbf{2}} \mathbf{h}\right)\right)\end{array}$ \\
\hline $\mathbf{0}$ & 433.2 \\
$\mathbf{1}$ & 462.1 \\
$\mathbf{3}$ & 570.5 \\
$\mathbf{5}$ & 543.7 \\
$\mathbf{7}$ & 471.3 \\
$\mathbf{1 0}$ & 456.2 \\
\hline
\end{tabular}

\subsection{Antioxidant activity evaluation (DPPH assay)}

During the healing process, the oxidative stress results from the accumulation of the generated free radicals at the wound site results in DNA breakage, protein inactivation, etc. The antioxidant ability of the essential oils may help in the scavenging excess free radicals which is one of the most substantial requirements for successful wound healing[36]. DPPH assay was used to evaluate the antioxidant activity of the (Psy-Carp) hydrogel dressings incorporated different concentations of (FO) essential oil compared to unirradiated (FO) oil sample and the obtained results were represented in Table (2). The results indicated that there is a marked increase in the DPPH scavenging activity for the evaluated (Psy-Carp)/FO hydrogel dressings prepared at $15 \mathrm{kGy}$ compared to that of the un-irradiated free FO oil sample. These findings come in good agreement with similar studies reported by Zantar et al. (2015) and Ademo et al. (2004) in which they attributed the increase in the antioxidant activity after irradiation to the degradation of molecules to other phenolic molecules or because of the changes in the conformation of molecules that contribute in antioxidant activity[37, 38]. The appropriate antioxidant efficiency of the (PsyCarp)/FO hydrogel dressings can prevent oxidative damage which facilitates tissue repair and healing in chronic wounds which make them a promising candidate in the wound healing process. 

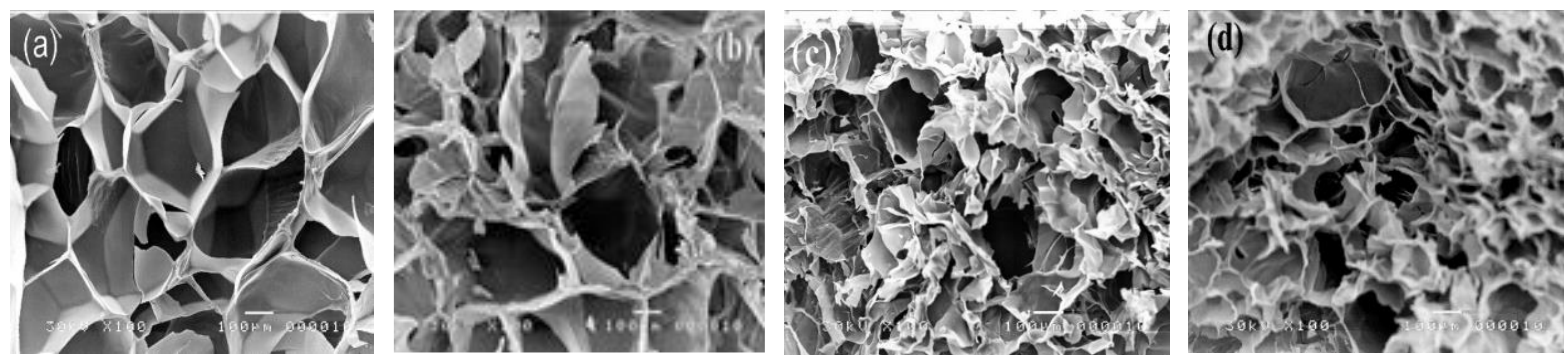

Fig. (3): SEM micrograph of (Psy-carp)/FO dressing hydrogels of different FO oil content: (a) $0 \%$, (b) $1 \%$, (c) $5 \%$ and (d) $10 \%$.

Table (2): Free radical scavenging activities (\%) of (Psycarp)/FO dressing hydrogels with different FO oil content $(\%)$.

\begin{tabular}{cc}
\hline $\begin{array}{c}\text { Oil content } \\
(\boldsymbol{\%})\end{array}$ & DPPH scavenging $(\boldsymbol{\%})$ \\
\hline Free oil (un-irradiated \\
sample) \\
$\mathbf{0}$ oil & 70.9 \\
$\mathbf{1}$ & 16.9 \\
$\mathbf{3}$ & 73.4 \\
$\mathbf{5}$ & 75.5 \\
$\mathbf{7}$ & 77.8 \\
$\mathbf{1 0}$ & 79.8 \\
\hline
\end{tabular}

\subsection{Hemolytic potential}

Following the Council of Europe guidelines [39] and the US FDA guidelines[40], dressing materials were classified into hemolytic (hemolysis over 5\%), slightly hemolytic (hemolysis between $2 \%$ and $5 \%$ ) and nonhemolytic (below 2\%). The blood compatibility of the (Psy-Carp)/FO hydrogel dressings were evaluated spectrophotometrically by measuring the amount of the released hemoglobin after the incubation with the dressing samples. The hemolytic index (\%) data represented in Table(3) was less than $2 \%$ which indicates no significant haemolytic behavior ensuring good blood compatibility and safely usage for all the dressing samples.

Table (3): Hemolytic index for (Psy-carp)/FO hydrogel dressings with different $\mathrm{FO}$ oil content.

\begin{tabular}{cc}
\hline FO oil content $(\mathbf{w t} \%)$ & Hemolytic index $(\boldsymbol{\%})$ \\
\hline $\mathbf{0}$ & 0.51 \\
$\mathbf{1}$ & 0.47 \\
$\mathbf{3}$ & 0.46 \\
$\mathbf{5}$ & 0.49 \\
$\mathbf{7}$ & 0.53 \\
$\mathbf{1 0}$ & 0.65 \\
\hline
\end{tabular}

\subsection{Assessment of the antimicrobial activity}

\subsubsection{Total plate count}

Figure (4) demonstrates the antimicrobial activity of (Psy-Carp)/FO hydrogel dressings containing different concentrations of (FO) essential oil against Staphylococcus aureus (S. aureus), Escherichia coli (E. coli) and Candida albicans (C.albicans) as representatives of (Gram-positive), (Gram-negative) bacteria and fungi, respectively assessed by calculating the log change in the viable count compared with the oilfree (Psy-Carp) dressing.

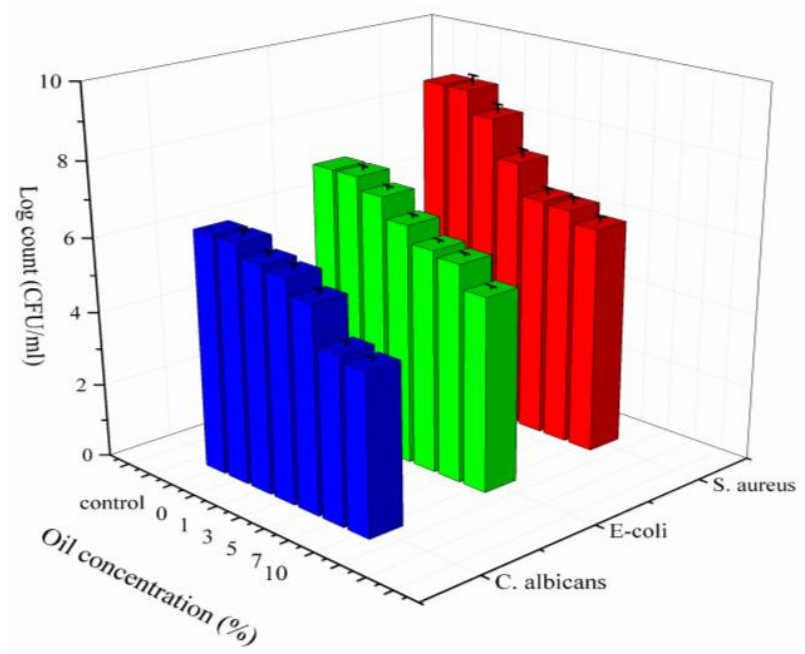

Fig. (4): Viable count of S.aureus, E.coli and Candida albicans incubated with (Psy-Carp)/FO hydrogel dressings of different FO oil content (wt\%)

As is clear, for all the tested strains incubated with the control and oil-free (Psy-Carp) dressing, the number of survivors of the applied strains increased during the $18 \mathrm{~h}$ contact time. On the other hand, the tested strains incubated with (Psy-Carp)/FO dressings suffered an increasing shortage in the log number of survivors by $2 \log$ cycles for all the tested strains at the end of contact time. 
The efficient antimicrobial activity of the (PsyCarp)/FO hydrogel dressings may be attributed to the oil's chemical constituents which are mainly monoterpenes and sesquiterpenes, such as alpha-pinene, Limonene, alpha-Thujene, and beta-Pinene with small amounts of diterpenoid components being the upper limit in terms of molecular weight[41-43]. Some researchers have reported that monoterpene or sesquiterpene hydrocarbons and their oxygenated derivatives, which are the major components of essential oils, exhibit potential antimicrobial activities[44]. These findings strongly supported the results of this study as (FO) essential was also found to contain these components, which confirmed its efficacy as a natural antimicrobial agent.

\subsubsection{Time killing assay}

The antibacterial activity of (Psy-carp) hydrogel dressing with $10 \%$ (FO) oil against the tested microbial strains was examined by time- killing assay. All suspensions from the tested strains were incubated with (Psy-carp) hydrogel dressing with 10\% (FO) oil and then the change in the number of viable cells was measured over time and represented in Figure (5). As can be seen, there was a significant reduction in the number of viable cells during the first two hours for all the tested strains. The high rate of microbial killing observed in the current study suggests that the (Psy-carp)/FO hydrogel dressings have highly potent antimicrobial activity that may have potential medical applications.

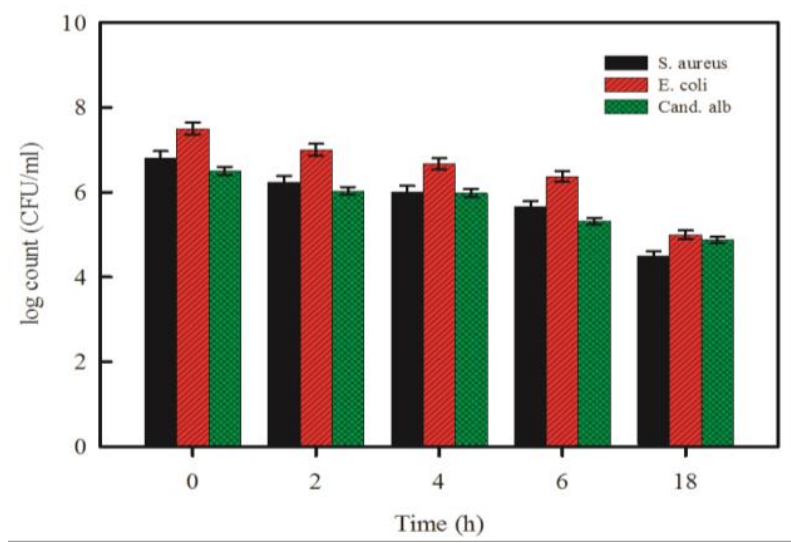

Fig. (5): Time-dependent viable cell count for (ロ) S.aureus ( $\square$ ) E.coli and ( $\square$ ) Candida albicans incubated with (PsyCarp)/10\% FO hydrogel dressing

\subsubsection{Protein content determination}

Further investigations were carried out to explore the possible mechanism of action of the compound containing essential oil on microbial cells. The release of proteins from the microbial cells is considered as an indication of the reduction in their cell membrane integrity. Cell content release was determined from measurements of the increase in absorbance at $600 \mathrm{~nm}$ as it is illustrated in Table (4). The results revealed that there was a slight increase in the protein content with the control group, which can be attributed to the death of some of the bacteria in their normal life cycle since this causes protein release. While there was a significant increase in the protein content released from all the tested microbial cells that occurred after 2,6 , and $18 \mathrm{~h}$ of incubation with (Psy-Carp)/10 \%FO hydrogel dressings compared to the control groups. These results suggest that the integrity of the tested strains cell membranes was altered after the incubation with (Psy-Carp)/ 10 $\% \mathrm{FO}$ hydrogel dressings, leading to protein release into the culture medium. Disruption of cell membranes and loss of cell constituents is a strong indication for cellular malfunction and death. He et al., (2014) reported that the increase in the concentration of protein can be attributed to the damage done by the essential oil to the $E$. coli cell membrane[45].

\subsubsection{Quantification of the Exopolysaccharides}

As illustrated in Figure (6), there was a significant decrease in the number of exopolysaccharides (EPS) from 1.009 to 0.56 , from 0.8 to $0.52 \mathrm{mg} / \mathrm{l}$ and 0.67 to $0.43 \mathrm{mg} / \mathrm{l}$ with S.aureus, E.coli, and C. albicans, respectively. The EPS is a major feature of biofilms of the microbes and is believed to play a major role in their resistance. The EPS is believed to work in three ways that include; a diffusion barrier, a molecular sieve, and an adsorbent. As a diffusion barrier, it prevents the complete penetration of antimicrobial agents and macromolecules into the inner cells[46]. Due to the negative charge on the EPS, penetration of molecules may also be restricted by the charge attraction and thus become adsorbed onto the matrix[47]. In addition to restricted penetration, other mechanisms are believed to be coupled to the EPS thereby enhancing resistance. Slow penetration of drugs is believed to be coupled with either degradation or inactivation of the drug during the process.

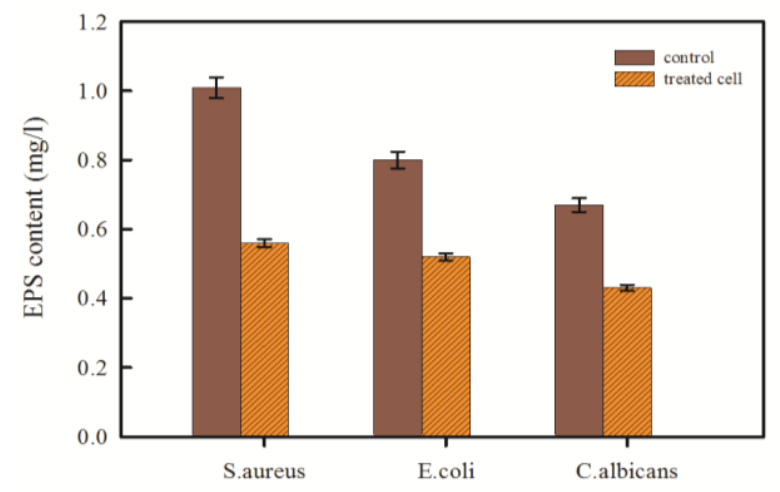

Fig. (6): Exopolysaccharides content of the three strains incubated with (Psy-Carp)/ (FO) hydrogel dressings. Results represent the mean of three replicates. Values are the mean \pm standard error. 
Table (4): Protein content determination before and after incubation with (Psy-carp)/ (FO) hydrogel dressing containing 10\% (FO) essential oil at time intervals.

\begin{tabular}{c|c|c|c|c|c|c}
\hline \multirow{2}{*}{ Time (h) } & \multicolumn{7}{c}{ Protein content $(\mathbf{m g} / \mathbf{m l})$} \\
\cline { 2 - 7 } & \multicolumn{2}{c}{ S.aureus } & \multicolumn{2}{c}{ E.coli } & \multicolumn{2}{c}{ Cand. alb } \\
\cline { 2 - 8 } & before & after & before & after & before & after \\
\hline $\mathbf{0}$ & $0.055 \pm 0.005$ & $0.067 \pm 0.004$ & $0.076 \pm 0.002$ & $0.079 \pm 0.006$ & $0.126 \pm 0.008$ & $0.168 \pm 0.002$ \\
$\mathbf{2}$ & $0.236 \pm 0.015$ & $0.507 \pm 0.016$ & $0.079 \pm 0.006$ & $0.416 \pm 0.034$ & $0.199 \pm 0.012$ & $0.516 \pm 0.023$ \\
$\mathbf{4}$ & $0.351 \pm 0.020$ & $1.243 \pm 0.040$ & $0.199 \pm 0.010$ & $0.768 \pm 0.030$ & $0.236 \pm 0.015$ & $0.686 \pm 0.031$ \\
$\mathbf{6}$ & $0.552 \pm 0.045$ & $1.996 \pm 0.096$ & $0.217 \pm 0.020$ & $1.313 \pm 0.030$ & $0.351 \pm 0.020$ & $1.571 \pm 0.029$ \\
$\mathbf{1 8}$ & $0.686 \pm 0.030$ & $3.702 \pm 0.050$ & $0.516 \pm 0.020$ & $2.093 \pm 0.050$ & $0.428 \pm 0.030$ & $1.996 \pm 0.094$ \\
\hline
\end{tabular}

** Values are means \pm standard deviation

Table (5): The follow-up for S. aureus, E. coli, and C. albicans penetration through (Psy-Carp)/FO dressings on nutrient agar medium after one week of daily inspection

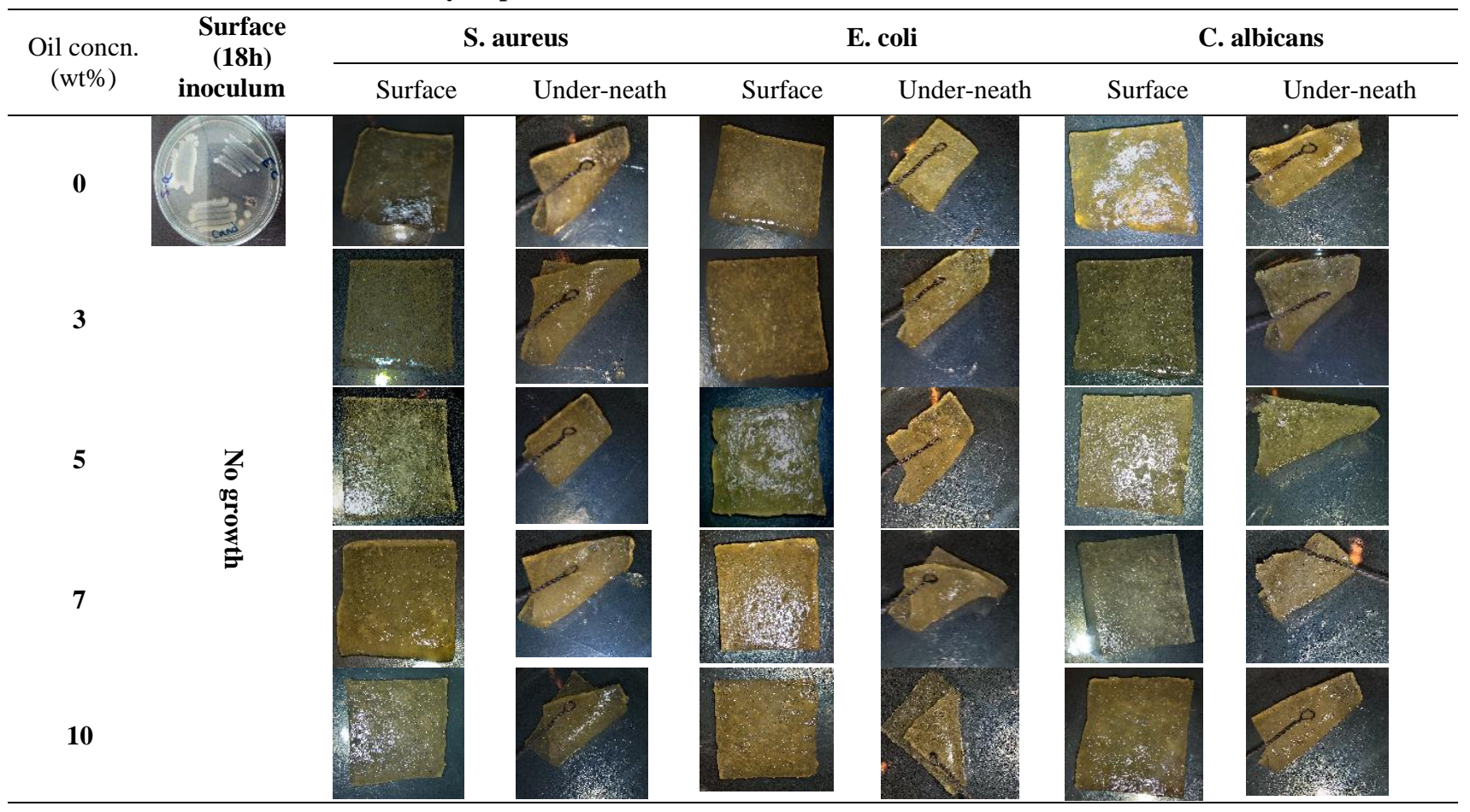

\subsubsection{Microbial Surface Charge - Zeta Potential Measurement}

Zeta potential measurements are carried out to evaluate the membrane surface potential of the tested microbial cells after the incubation with (Psy-Carp)/FO hydrogel dressings. As shown in Figure (7), the microbial cells that did not incubate with the (PsyCarp)/FO hydrogel dressings display zeta potential of 20, -25 , and $-18 \mathrm{mV}$ for $S$. aureus, E. coli, and $C$. albicans, respectively. However, zeta potential values were decreased after their incubation with (PsyCarp)/FO dressings.
Details on the membrane potential and reflections on the microbial metabolic state can be ascertained using the zeta potential measurement, whereby higher growth rates produce a more negative reading[48, 49]. Under normal physiological circumstances, microbial cell surfaces are usually negatively charged-due to the presence of anionic groups in their membranes. The obtained data demonstrated that the cells carried a reduced negative charge after exposure to (Psy-Carp)/FO dressing with $10 \%$ essential oil. It is suggested that the irreversible membrane damage was caused by the acidifying and protein denaturation of the cell membrane due to the accumulation of the components of the essential oil[50]. 


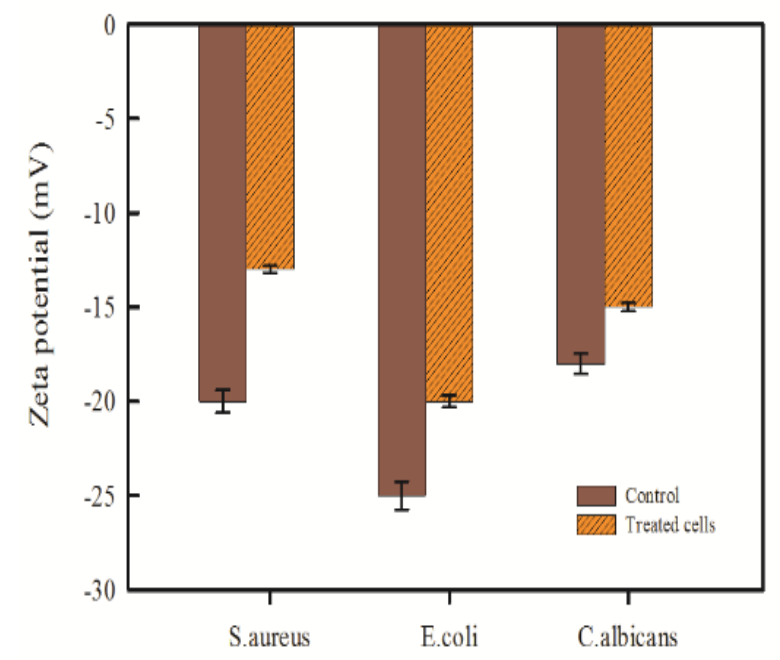

Fig. (7): Microbial surface charge-Zeta potential of tested strains incubated with (Psy-Carp)/FO dressings. Results represent the mean of three replicates. Values are the mean \pm standard error.

\subsubsection{Microbial barrier potency}

An ideal wound dressing should protect wounds from microbial invasion which results in exudate accretion that delays wound healing with increased chance of scare formation. As it is obvious from the photographic pictures represented in Table (5), the results of one-week-long examination for $S$. aureus, $E$. coli and C. albicans penetration through (Psy-Carp)/FO dressings ensure the dressing's ability to prevent microbial penetration efficiently as indicated by the clear growth zone underneath the dressing area on the agar plates along the experiment period. Another important advantage is that, (Psy-Carp)/FO dressings not only prevent the microbial penetration through it but also inhibit their growth on its surface as confirmed by the surface swap re-culturing after one day of examination. The microbial barrier potency of the (Psy-Carp)/FO hydrogel dressings is mainly due to synergistic effect for the bulk structure integrity of the hydrogel matrix[51] and the natural antimicrobial activity of the FO essential oil due to its hydrophobicity and phenolic constituents that can prevent microbe penetration[52]

\subsection{In vivo wound healing evaluation}

Wound healing immediately starts after an injury and proceeds with a complicated but well-organized interaction among various types of tissues and cells. The injury causes a gap, which is immediately filled by clots in the presence of platelet aggregates. For the skin wound-healing process the inflammatory phase starts with leukocytes such as neutrophils and monocytes infiltration to the site, remove the breakdown products from the injured cells and clots, and release various growth factors and cytokines [53].

\subsubsection{Anti-inflammatory response}

Biochemical analysis of wound site skin homogenate significantly indicated the antiinflammatory effect of the applied dressings presented by a significant decrease of IL- 6 parallel to the dressing FO oil content. An important step in wound healing is the production of inflammatory cytokine, IL- 6 has crucial roles in inflammation, particularly in the early phase [54]. IL-6 is produced by various types of cells, including neutrophils, macrophages, and fibroblasts accumulated in the wound site after skin incisions macrophages[55, 56]. IL-6 deficiency markedly affects all three phases of wound healing, inflammation, proliferation, and remodeling, respectively[57]. IL-6deficient mice showed diminished, inflammatory, acutephase response after tissue damage or infection, reduction in leukocyte infiltration which supports the suggestion of involvement of IL-6 in wound healing[58]. The present study showed intensive production of IL- 6 at the site of skin injury in the injured skin of the control which was not treated with the dressing, while a significant decrease in IL-6 was observed with the increase in FO oil content in the applied dressings indicating anti-inflammatory of the dressing contains a high concentration of the oil (5 and 10\%), as illustrated in Figure (8).

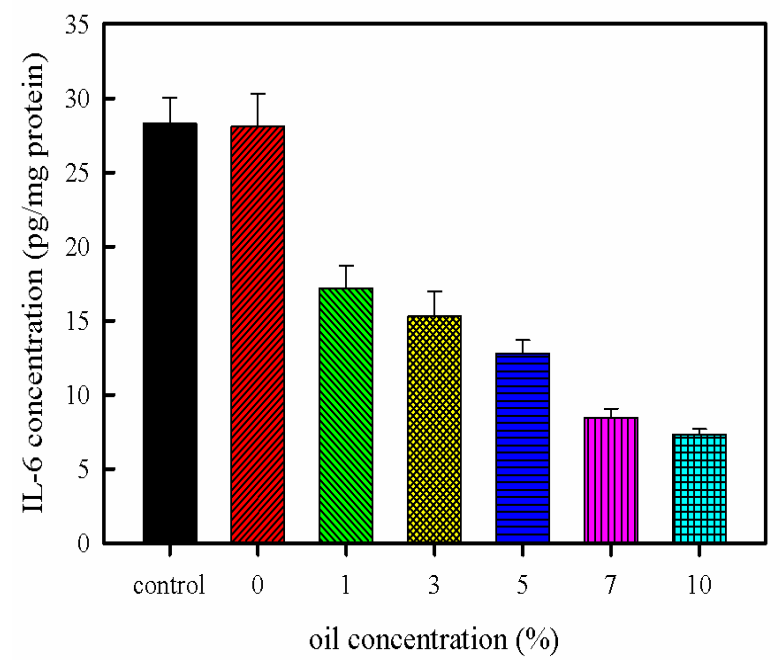

Fig. (8): Inflammatory response of wounded rat skin treated with (Psy-carp)/FO hydrogel dressings of different FO oil content $(\%)$. a: significance compared to control. 


\subsubsection{Wound Remodeling}

Wound remodeling is a step activated by produced cytokines at the injury site. Our results presented a wound site renewing through provoke of MMP-9 and Nf-kb. Results clarifying high levels of MMP-9 and Nf$\mathrm{kb}$ in wound site treated with dressing of $0 \% \mathrm{FO}$ oil compared to normal control skin. MMP-9 and Nf-kb in wound site treated with the dressing of FO oil content, showed reduced levels compared to that of FO oil $0 \%$ proportion to oil content, Figure (9). Comparing these results with that of IL-6 data, we may suggest that MMP-9 and Nf-kb content were reduced due to the reduction in IL-6 at the $20^{\text {th }}$ day in wounds treated with high FO oil \% content compared with the control suggesting an anti-inflammatory effect of FO oil concerning its concentration.

Metalloproteinase (MMPs) play a crucial role in all stages of wound healing by modifying the wound matrix, allowing for cell migration and tissue remodeling. MMP9 plays an important role in keratinocyte migration; it is expressed at the leading edges of migrating keratinocytes during wound closure. MMP-9 knockout (KO) mice display delayed wound closure indicates its importance in wound healing and cell signaling. MMP-9 and MMP2 regulate angiogenesis during wound healing through the activation of proangiogenic cytokines, including TNF-a and VEGF[59, 60]. The treatment of (Psycarp)/FO hydrogel dressings may enhance wound healing through regulating the canonical $\mathrm{NF}-\kappa \mathrm{B}$ signaling pathway [61], Nf- $\kappa \mathrm{B}$ is essential for wound healing as it activates the innate immune reaction, proliferation, and migration of cells, regulate of MMP expression, cytokines, and growth factors[62].

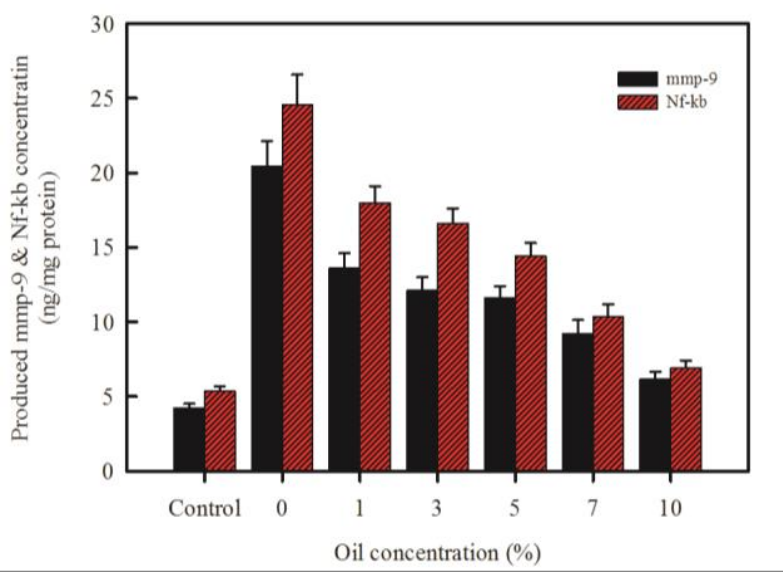

Fig. (9): Accumulative production for MMP-9 and Nf-kb in the wounded skin concerning FO oil content (\%) incorporated in the (Psy-Carp)/FO hydrogel dressings. a: significance compared to control of MMP-9 of control group, b: significance compared to Nf-kb of control group.

\subsubsection{Wound closure and antimicrobial potential}

In this study, the rate of wound closure for each wound has been evaluated on $5^{\text {th }}, 10^{\text {th }}, 15^{\text {th, }}$ and $20^{\text {th }}$-day post wounding and the extent of wound closure along 20 days of observation was also quantified and the results are shown in Figure 10 ( $\mathrm{a}$ and $\mathrm{b}$ ). The wound healing process showed progress up to $20^{\text {th }}$ days with significant differences among the treatment groups. Wounds treated with (Psy-Carp)/FO hydrogel dressings showed healing efficacy in a shorter time compared to the control. Upon using (Psy-Carp)/FO hydrogel dressings, the wound healing reached $98.82 \%$ compared to the control.

More importantly, wound closure is positively related to the dressing's frankincense essential oil (FO) content, noticing that, $10 \%$ oil content showed good wound closure compared to other treatments. Five days after surgery, the wound treated with 10\% (PsyCarp)/FO hydrogel dressing appears significant closure higher than that of 7 and $5 \%$ by $16.86 \%$ while reached to $24.15 \%$ and $26 \%$ compared to that of 3 and $5 \%$ oil content. After 20 days of surgery, the wound closure of wounds treated with (Psy-carp)/ 10\% FO hydrogel dressings was higher than that contain $7,5,3$, and $1 \%$ oil content by $3.36 \%, 9 \%, 13.44 \%$, and $16.87 \%$, respectively.

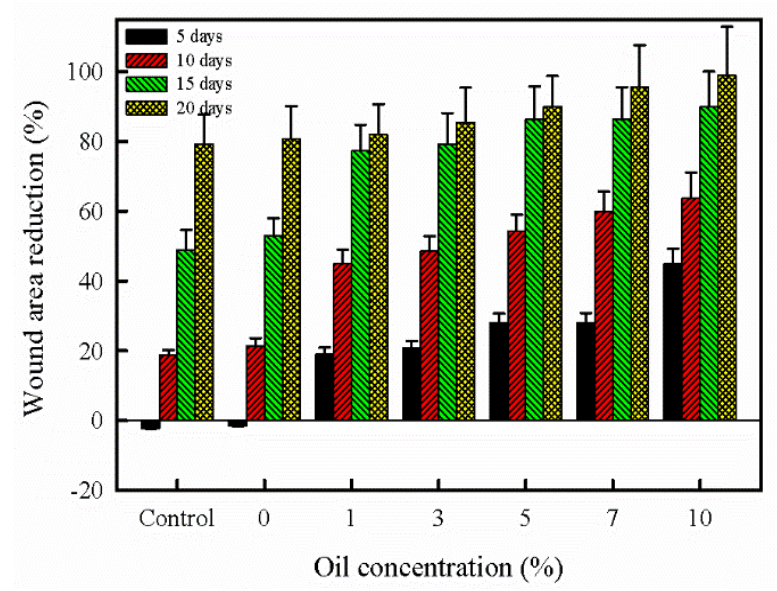

Fig. (10-a): Wound closure \% of wounded skin concerning FO oil content $(\%)$ incorporated in the (Psy-Carp)/FO hydrogel dressings. (negative values in the direction of the negative axis indicated the wound deteriorated and enlarged). Significance a: compared to 5 days control, b: compared to $\mathbf{1 0}$ days control, c: compared to 15 days control, d: compared to 20 days control 


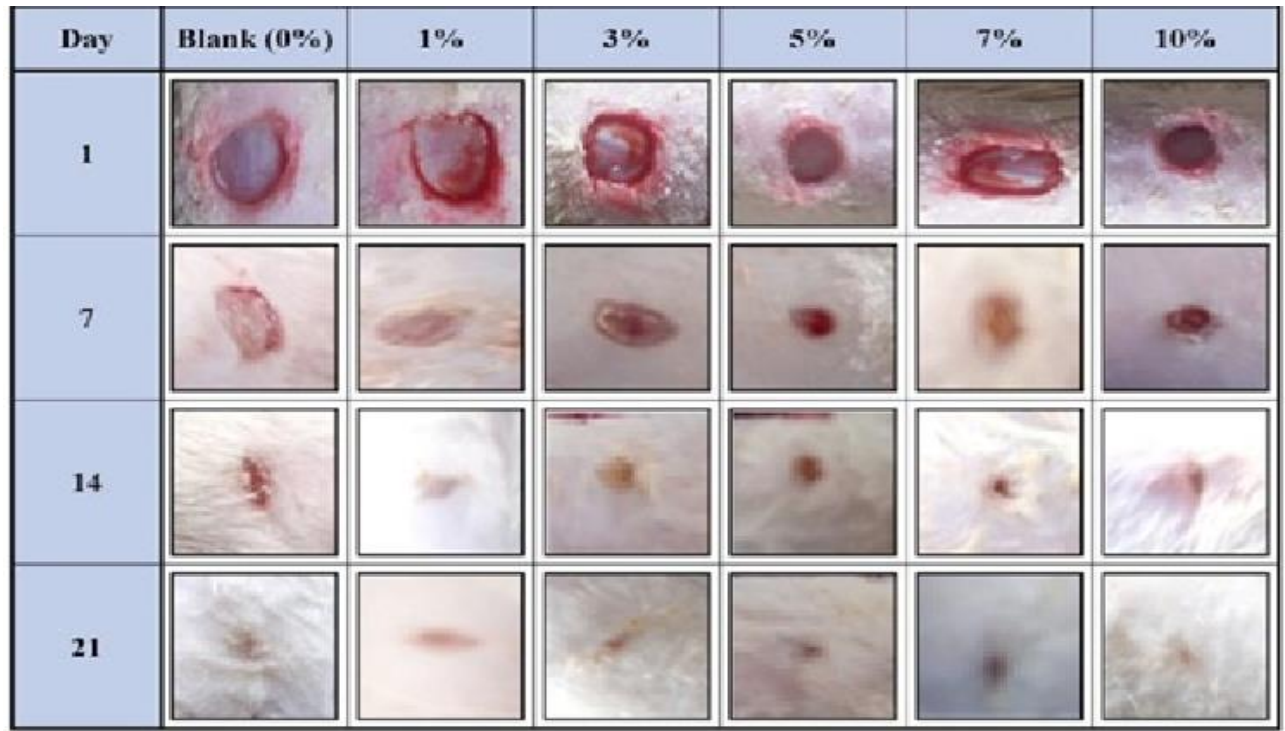

Fig. (10-b): Visual observation photographs of skin wound healing development in response to FO oil content (\%) incorporated in the (Psy-Carp)/FO hydrogel dressings.

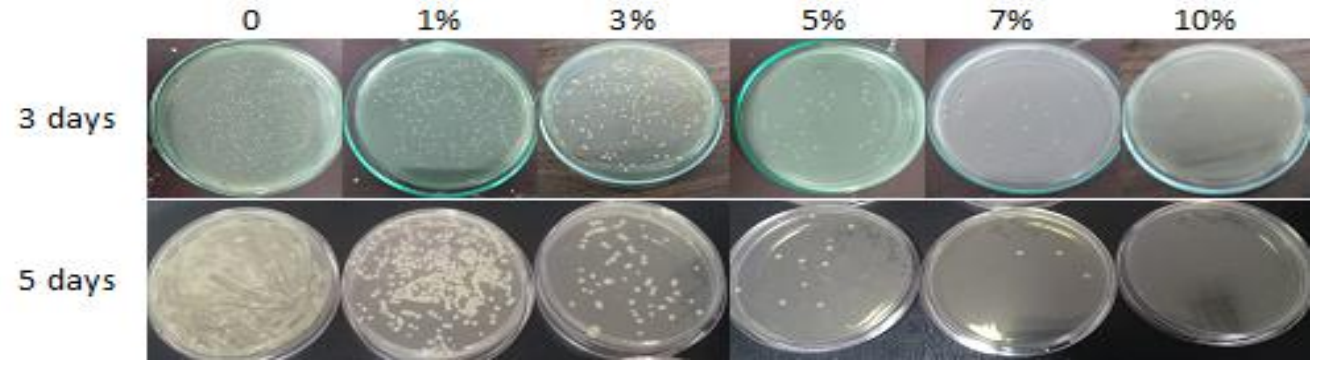

Fig. (11): Microbial isolates from the mice wound on day 3 and day 5 after surgery

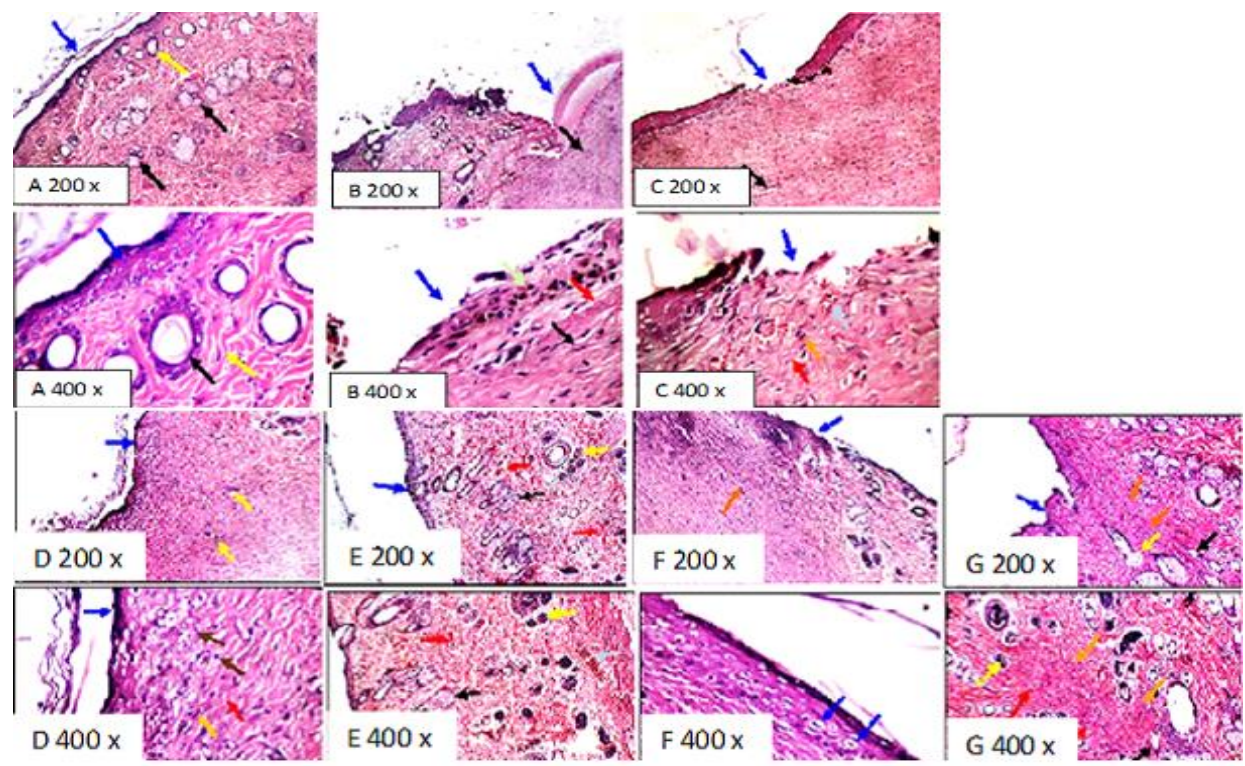

Fig. (12): Photos of skin histological sections: slide A (Control); slide B (Wound + (Psy-Carp) dressing; slide C (PsyCarp)/1\%FO; slide D (Psy-Carp)/3\%FO; slide E (Psy-Carp)/5\%FO; slide F (Psy-Carp)/7\%FO; slide G (PsyCarp)/10\%FO. blue arrow: epidermis, yellow arrow: hair follicle, red arrow: collagen, black arrow: pilosebaceous, mint arrow: inflammatory cells, mustard arrow: fibroblasts, light blue arrow: congested blood vessels, brown arrow: inflammatory infiltrate, orange arrow: area under the scar, green arrow: blood vessels. 
The antimicrobial potential of the FO/dressings on mice wounds was evaluated by culturing the exudates from the wound on day 3 and day 5 after surgery and observing the colonies of each culture and the obtained data was illustrated in Figure (11). As can be seen, wounds treated with FO/dressings show the lowest number of microbial colonies and the antimicrobial efficiency increased as the FO dressing's content increased due to the excellent antimicrobial potency of the FO essential oil.

\subsubsection{Histopathological findings}

Histopathological findings of treated wound sections were used to evaluate the (Psy-Carp)/FO hydrogel dressings efficacy in wound healing. As it can be seen from Figure (12), after 20 days of the wound treatment with(Psy-carp)/FO hydrogel dressings of different FO oil content, histopathological analysis of untreated wound section (control) showed ulcerated epidermis with underlying large scar tissue composed of fibroblasts, collagen fibers, and few inflammatory cells, no pilosebaceous units or hair follicles in the scar tissue Figure(12-a). While wounded skin treated with (PsyCarp)/1(\%)FO hydrogel dressing showed small ulcer in the non-keratinized epidermis with underlying large scar tissue composed of dilated congested blood vessels and proliferating fibroblasts with collagen formation and few inflammatory cells, and small hair follicles with no pilosebaceous units in the scar tissue Figure (12-b). Wounded skin treated with (Psy-Carp)/3(\%) FO dressing showed thin intact keratinized epidermis with vacuolated keratinocytes and underlying large scar tissue composed of fibroblasts with collagen formation and moderate inflammatory infiltrate, and small hair follicles with no pilosebaceous units in the scar tissue Figure (12-c). Wounded skin healed by using (Psy-carp)/5(\%) FO hydrogel dressing showed intact keratinized epidermis with underlying minimal scar tissue composed of few fibroblasts with excess thick collagen, dilated congested blood vessels, and few scattered inflammatory cells, and pilosebaceous units and hair follicles Figure (12-d). Wounded skin treated with dressing with (PsyCarp)/7(\%) FO hydrogel dressing showed less healing properties. Healed skin showed partially ulcerated minimally keratinized epidermis with vacuolated keratinocytes, underlying large scar tissue composed of fibroblasts with collagen formation few blood vessels, and small hair follicles with no pilosebaceous units in the scar tissue Figure (12-e). Finally, wounded skin treated using (Psy-Carp)/5(\%) FO hydrogel dressing showed intact keratinized epidermis with underlying minimal scar tissue composed of fibroblasts with collagen formation, and few small-sized pilosebaceous units and hair follicles Figure (12-f). In conclusion, (PsyCarp)/FO hydrogel dressing incorporated 5 and 10\% FO essential oil, respectively exhibits the best woundhealing efficiency.

\section{CONCLUSION}

By using gamma irradiation technique, a novel hydrogel dressings composed of Psyllium and Carbopol incorporated Frankincense oil has been prepared to maximize the benefits of Frankincense oil such as disinfection and healing properties. During this study, (Psy-Carp) dressings containing five different (FO) oil concentrations $(1: 10 \mathrm{wt} \%)$ were prepared, and their effect on the physicochemical properties. antioxidant activity and haemocompatibility of the dressing were evaluated. The incorporation of FO oil within the (PsyCarp) hydrogel network enhances their swelling degree and water vapor transmittance properties as well. The incorporation of FO oil results in foliate porous network appearance. (Psy-Carp)/FO hydrogel dressings show a marked antioxidant efficiency which makes them a promising candidate in the wound healing process. (PsyCarp)/FO hydrogel dressings show excellent barrier potency against external microorganism attack and efficient antimicrobial activities against $S$. aureus, $E$. coli, and $C$. albicans, respectively. In vivo wound healing evaluation using rat model confirms that (PsyCarp)/FO hydrogel dressings induce faster wound healing with a marked increase in Nf-kb when compared with that of FO free (Psy-Carp) hydrogel. Based on the above-mentioned results, it can be concluded that (PsyCarp)/FO hydrogel dressings demonstrate a promising potential as wound care candidates.

\section{Declaration of conflicting Interests}

The author(s) declared no potential conflicts of interest concerning the research, authorship, and/or publication of this article.

\section{REFERENCES}

[1] Erfurt-Berge, C. and Renner, R., Recent developments in topical wound therapy: impact of antimicrobiological changes and rebalancing the wound milieu. 04/15 ed. BioMed research international. Vol. 2014. 2014: Hindawi Publishing Corporation. 819525-819525.

[2] Sen, C.K., Gordillo, G.M., Roy, S., Kirsner, R., Lambert, L., Hunt, T.K., Gottrup, F., Gurtner, G.C., and Longaker, M.T. (2009) Human skin wounds: a major and snowballing threat to public health and

Arab J. Nucl. Sci. Appl., Vol. 54, 2, (2021) 
the economy, Wound repair and regeneration : official publication of the Wound Healing Society [and] the European Tissue Repair Society. 17(6): 763-771.

[3] Boateng, J. and Catanzano, O. (2015) Advanced Therapeutic Dressings for Effective Wound Healing-A Review, Journal of Pharmaceutical Sciences. 104(11): 3653-3680.

[4] Parani, M., Lokhande, G., Singh, A., and Gaharwar, A.K. (2016) Engineered Nanomaterials for Infection Control and Healing Acute and Chronic Wounds, ACS Applied Materials \& Interfaces. 8(16): 10049-10069.

[5] Arya, G., Sharma, N., Ahmed, J., Gupta, N., Kumar, A., Chandra, R., and Nimesh, S. (2017) Degradation of anthropogenic pollutant and organic dyes by biosynthesized silver nano-catalyst from Cicer arietinum leaves, $\mathrm{J}$ Photochem Photobiol B. 174: 90-96.

[6] Eming, S.A., Martin, P., and Tomic-Canic, M. (2014) Wound repair and regeneration: mechanisms, signaling, and translation, Science translational medicine. 6(265): 265sr6-265sr6.

[7] Ibrahim, N., Wong, S.K., Mohamed, I.N., Mohamed, N., Chin, K.Y., Ima-Nirwana, S., and Shuid, A.N. (2018) Wound Healing Properties of Selected Natural Products, Int J Environ Res Public Health. 15(11).

[8] Madaghiele, M., Demitri, C., Sannino, A., and Ambrosio, L. (2014) Polymeric hydrogels for burn wound care: Advanced skin wound dressings and regenerative templates, Burns \& trauma. 2(4): 153161.

[9] Drury, J.L. and Mooney, D.J. (2003) Hydrogels for tissue engineering: scaffold design variables and applications, Biomaterials. 24(24): 4337-51.

[10] Koehler, J., P. Brandl, F., and M. Goepferich, A., Hydrogel Wound Dressings for Bioactive Treatment of Acute and Chronic Wounds. Vol. 100. 2018.

[11] Kamoun, E.A., Kenawy, E.-R.S., and Chen, X. (2017) A review on polymeric hydrogel membranes for wound dressing applications: PVA-based hydrogel dressings, Journal of advanced research. 8(3): 217-233.

[12] Ponrasu, T., Veerasubramanian, P.K., Kannan, R., Gopika, S., Suguna, L., and Muthuvijayan, V. (2018) Morin incorporated polysaccharide-protein (psyllium-keratin) hydrogel scaffolds accelerate diabetic wound healing in Wistar rats, RSC Advances. 8(5): 2305-2314.

[13] Miraftab, M., Masood, R., and Edward-Jones, V. (2014) A new carbohydrate-based wound dressing fibre with superior absorption and antimicrobial potency, Carbohydr Polym. 101: 1184-90.

[14] Singh, B. (2007) Psyllium as therapeutic and drug delivery agent, Int J Pharm. 334(1-2): 1-14.

[15] Singh, B. and Dhiman, A. (2017) Evaluation of Gentamicin and Lidocaine Release Profile from Gum Acacia-crosslinked-poly(2hydroxyethylmethacrylate)-carbopol Based Hydrogels, Current Drug Delivery. 14(7): 981-991.

[16] Chirayath, R.B., A, A.V., Jayakumar, R., Biswas, R., and Vijayachandran, L.S. (2019) Development of Mangifera indica leaf extract incorporated carbopol hydrogel and its antibacterial efficacy against Staphylococcus aureus, Colloids Surf B Biointerfaces. 178: 377-384.

[17] Singh, S., Anjum, S., Joy, J., and Gupta, B., Polysaccharide-Aloe vera Bioactive Hydrogels as Wound Care System, in Cellulose-Based Superabsorbent Hydrogels, M.I.H. Mondal, Editor. 2019, Springer International Publishing: Cham. p. 1473-1490.

[18] Gunes, S. and Tihminlioglu, F. (2017) Hypericum perforatum incorporated chitosan films as potential bioactive wound dressing material, Int $\mathrm{J}$ Biol Macromol. 102: 933-943.

[19] Han, X., Rodriguez, D., and Parker, T.L. (2017) Biological activities of frankincense essential oil in human dermal fibroblasts, Biochimie Open. 4: 3135.

[20] Hamidpour, R., Hamidpour, S., Hamidpour, M., and Shahlari, M. (2013) Frankincense ( rǔ xiāng; boswellia species): from the selection of traditional applications to the novel phytotherapy for the prevention and treatment of serious diseases, Journal of traditional and complementary medicine. 3(4): 221-226.

[21] Chouhan, S., Sharma, K., and Guleria, S. (2017) Antimicrobial Activity of Some Essential OilsPresent Status and Future Perspectives, Medicines (Basel, Switzerland). 4(3): 58.

[22] Simões, D., Miguel, S.P., Ribeiro, M.P., Coutinho, P., Mendonça, A.G., and Correia, I.J. (2018) Recent advances on antimicrobial wound dressing: A 
review, European Journal of Pharmaceutics and Biopharmaceutics. 127: 130-141.

[23] Seow, Y.X., Yeo, C.R., Chung, H.L., and Yuk, H.G. (2014) Plant essential oils as active antimicrobial agents, Crit Rev Food Sci Nutr. 54(5): 625-44.

[24] Sandra Gustaitea, J.K., J. Bobokalonova, Stefano Pernib, Victoria and Dutschkc, J.L., Polina Prokopovichb, $\mathrm{d}^{*}$ (2015) Characterization of cellulose based sponges for wound dressings, Colloids and Surfaces A: Physicochemical and Engineering Aspects. 480: 336-342.

[25] Singh, B. and Dhiman, A., Designing bio-mimetic moxifloxacin loaded hydrogel wound dressing to improve antioxidant and pharmacology properties. Vol. 5. 2015.

[26] Tomić, S.L., Mićić, M.M., Dobić, S.N., Filipović, J.M., and Suljovrujić, E.H. (2010) Smart poly(2hydroxyethyl methacrylate/itaconic acid) hydrogels for biomedical application, Radiation Physics and Chemistry. 79(5): 643-649.

[27] AATCC test method 100-2004: Antibacterial finishes on textile material : Assessment of. . Developed in 1961, AATCC Committee RA31.

[28] Tyagi, P., Singh, M., Kumari, H., Kumari, A., and Mukhopadhyay, K. (2015) Bactericidal activity of curcumin I is associated with damaging of bacterial membrane, PLoS One. 10(3): e0121313.

[29] Lowry, O.H., Rosebrough, N.J., Farr, A.L., and Randall, R.J. (1951) Protein measurement with the Folin phenol reagent, J Biol Chem. 193(1): 265-75.

[30] Nehad, E.A. and El-Shamy, A.R., Physiological studies on the production of exopolysaccharide by Fungi. Vol. 1. 2010. 1303-1308.

[31] Chaplin, M.F. and Kennedy, J.F., Carbohydrate Analysis: A Practical Approach. 1994: ILR Press.

[32] Yap, P., Krishnan, T., Chan, K.-G., and Lim, E., Antibacterial Mode of Action of Cinnamomum verum Bark Essential Oil, Alone and in Combination with Piperacillin, Against a MultiDrug-Resistant Escherichia coli Strain. Vol. 25. 2014.

[33] Peng, Y. and Li, Y. (2014) Combined effects of two kinds of essential oils on physical, mechanical and structural properties of chitosan films, Food Hydrocolloids. 36: 287-293.
[34] Drozdov, A.D. and deClaville Christiansen, J. (2017) The effects of $p H$ and ionic strength on equilibrium swelling of polyampholyte gels, International Journal of Solids and Structures. 110111: 192-208.

[35] Fan, L., Yang, H., Yang, J., Peng, M., and Hu, J. (2016) Preparation and characterization of chitosan/gelatin/PVA hydrogel for wound dressings, Carbohydrate Polymers. 146: 427-434.

[36] Kant, V., Gopal, A., N Pathak, N., Kumar, P., Tandan, S., and Kumar, D., Antioxidant and antiinflammatory potential of curcumin accelerated the cutaneous wound healing in streptozotocin-induced diabetic rats. Vol. 20. 2014.

[37] Zantar, S., Haouzi, R., Chabbi, M., Laglaoui, A., Mouhib, M., Mohammed, B., Bakkali, M., and Zerrouk, M.H. (2015) Effect of gamma irradiation on chemical composition, antimicrobial and antioxidant activities of Thymus vulgaris and Mentha pulegium essential oils, Radiation Physics and Chemistry. 115: 6-11.

[38] Adamo, M., Capitani, D., Mannina, L., Cristinzio, M., Ragni, P., Tata, A., and Coppola, R. (2004) Truffles decontamination treatment by ionizing radiation, Radiation Physics and Chemistry. 71(1): 167-170.

[39] Cardigan, R. (2007) Guide to the Preparation, Use and Quality Assurance of Blood Components (13th edn), Transfusion Medicine. 17(6): 491-491.

[40] Makroo, R.N., Raina, V., Bhatia, A., Gupta, R., Majid, A., Thakur, U.K., and Rosamma, N.L. (2011) Evaluation of the red cell hemolysis in packed red cells during processing and storage, Asian Journal of Transfusion Science. 5(1): 15-17.

[41] Hayashi, S., Amemori, H., Kameoka, H., Hanafusa, M., and Furukawa, K. (1998) Comparison of Volatile Compounds from Olibanum from Various Countries, Journal of Essential Oil Research. 10(1): 25-30.

[42] Basar, S., Koch, A., and König, W.A. (2001) A verticillane-type diterpene from Boswellia carterii essential oil, Flavour and Fragrance Journal. 16(5): 315-318.

[43] Frank, A. and Unger, M. (2006) Analysis of frankincense from various Boswellia species with inhibitory activity on human drug metabolising cytochrome P450 enzymes using liquid chromatography mass spectrometry after 
automated on-line extraction, Journal of Chromatography A. 1112(1): 255-262.

[44] Cakir, A., Kordali, S., Zengin, H., Izumi, S., and Hirata, T. (2004) Composition and antifungal activity of essential oils isolated from Hypericum hyssopifolium and Hypericum heterophyllum, Flavour and Fragrance Journal. 19(1): 62-68.

[45] He, M., Wu, T., Pan, S., and Xu, X. (2014) Antimicrobial mechanism of flavonoids against Escherichia coli ATCC 25922 by model membrane study, Applied Surface Science. 305: 515-521.

[46] Costerton, J.W., Stewart, P.S., and Greenberg, E.P. (1999) Bacterial biofilms: a common cause of persistent infections, Science. 284(5418): 1318-22.

[47] Hugo, W.B. and Russell, A.D., Pharmaceutical Biotechnology. 2004, Blackwell publishing company, USA. p. 416-440.

[48] van der Mei, H.C., de Vries, J., and Busscher, H.J. (1993) Hydrophobic and electrostatic cell surface properties of thermophilic dairy streptococci, Applied and environmental microbiology. 59(12): 4305-4312.

[49] Tymczyszyn, E.E., del Rosario Diaz, M., GomezZavaglia, A., and Disalvo, E.A. (2007) Volume recovery, surface properties and membrane integrity of Lactobacillus delbrueckii subsp. bulgaricus dehydrated in the presence of trehalose or sucrose, J Appl Microbiol. 103(6): 2410-9.

[50] Borges, A., Ferreira, C., Saavedra, M.J., and Simoes, M. (2013) Antibacterial activity and mode of action of ferulic and gallic acids against pathogenic bacteria, Microb Drug Resist. 19(4): 256-65.

[51] Lu, G., Ling, K., Zhao, P., Xu, Z., Deng, C., Zheng, H., Huang, J., and Chen, J. (2010) A novel in situformed hydrogel wound dressing by the photocrosslinking of a chitosan derivative, Wound Repair and Regeneration. 18(1): 70-79.

[52] Shaik, M., Aluru, S., Sambasivarao, K., and Bhaskar, M., Antimicrobial activity of frankincense of Boswellia serrata. Vol. 3. 2014. 1095-1101.

[53] Kitamura, A., Minematsu, T., Nakagami, G., and Sanada, H. (2018) Assessment of histopathology of wounds based on protein distribution detected by wound blotting, SAGE Open Medicine. 6: 2050312118812220.
[54] Akira, S. and Kishimoto, T. (1992) IL-6 and NFIL6 in acute-phase response and viral infection, Immunol Rev. 127: 25-50.

[55] Sato, Y. and Ohshima, T. (2000) The expression of $m R N A$ of proinflammatory cytokines during skin wound healing in mice: a preliminary study for forensic wound age estimation (II), Int J Legal Med. 113(3): 140-5.

[56] Kondo, T. and Ohshima, T. (1996) The dynamics of inflammatory cytokines in the healing process of mouse skin wound: a preliminary study for possible wound age determination, Int J Legal Med. 108(5): 231-6.

[57] Lin, Z.Q., Kondo, T., Ishida, Y., Takayasu, T., and Mukaida, N. (2003) Essential involvement of IL-6 in the skin wound-healing process as evidenced by delayed wound healing in IL-6-deficient mice, J Leukoc Biol. 73(6): 713-21.

[58] Kopf, M., Baumann, H., Freer, G., Freudenberg, M., Lamers, M., Kishimoto, T., Zinkernagel, R., Bluethmann, H., and Kohler, G. (1994) Impaired immune and acute-phase responses in interleukin6-deficient mice, Nature. 368(6469): 339-42.

[59] Heljasvaara, R., Nyberg, P., Luostarinen, J., Parikka, M., Heikkilä, P., Rehn, M., Sorsa, T., Salo, T., and Pihlajaniemi, T., Generation of biologically active endostatin fragments from human collagen XVIII by distinct matrix metalloproteases. Vol. 307. 2005. 292-304.

[60] Kato, T., Kure, T., Chang, J.-H., Gabison, E.E., Itoh, T., Itohara, S., and Azar, D.T. (2001) Diminished corneal angiogenesis in gelatinase Adeficient mice, FEBS Letters. 508(2): 187-190.

[61] Park, Y.R., Sultan, M.T., Park, H.J., Lee, J.M., Ju, H.W., Lee, O.J., Lee, D.J., Kaplan, D.L., and Park, C.H. (2018) NF- $\kappa B$ signaling is key in the wound healing processes of silk fibroin, Acta Biomaterialia. 67: 183-195.

[62] Ambrozova, N., Ulrichova, J., and Galandakova, A. (2017) Models for the study of skin wound healing. The role of Nrf2 and NF-kappaB, Biomed Pap Med Fac Univ Palacky Olomouc Czech Repub. 161(1): 1-13. 